\title{
Systematic reviews and randomised controlled trials on open angle glaucoma
}

\author{
Richard Wormald ${ }^{1,2} \cdot$ Gianni Virgili $^{3} \cdot$ Augusto Azuara-Blanco $^{4}$
}

Received: 3 September 2019 / Revised: 16 October 2019 / Accepted: 5 November 2019 / Published online: 3 December 2019

(c) The Author(s), under exclusive licence to The Royal College of Ophthalmologists 2019

\begin{abstract}
Evidence for the effectiveness of interventions to prevent the progression of optic nerve damage in open angle glaucoma has evolved over the last 25 years. We describe that evolution through the systematic reviews on various aspects of the topic and how those reviews have highlighted the need for new trials. Though we can be confident that lowering pressure does indeed reduce the risk of progression, we still lack good evidence on the comparative effectiveness of different treatments not so much on lowering pressure but on preventing progression of the disease. This is true for different medicines, types of laser and especially for different surgical interventions. As always there is a need for more research, but this needs to be focussed on key uncertainties using core outcome sets which avoid research waste. Ultimately, our guidelines can be based on sound and comprehensive evidence of effectiveness.
\end{abstract}

\section{Introduction}

Despite a great many trials on patients with open angle glaucoma over many years, there remains much uncertainty. Undoubtedly, resources have been wasted and opportunities missed [1]. But we argue here that with systematic reviews, we are now in a better position to identify those uncertainties and design and execute high-quality studies to deal with them without further wastage of scarce resources.

Open angle glaucoma lends itself well to trial methodology being a chronic disease easy to define. That is once arguments over the borderline between definite disease and suspect disease have been resolved. It is a common and important cause of severely disabling sight loss though fortunately for proportionally few of those affected. But inequity means many more do so when the disease presents late with a younger age of onset and poor access to treatment [2].

Richard Wormald

R.wormald@ucl.ac.uk

1 NIHR Biomedical Research Centre at Moorfields Eye Hospital and UCL Institute of Ophthalmology, London, UK

2 London School of Hygiene and Tropical Medicine, London, UK

3 University of Florence, Firenze, Italy

4 Queens University Belfast, Belfast, UK
Sir Peng Khaw has eloquently defined the ideal scenario; an intervention which takes $10 \mathrm{~min}$. costs $\$ 10$, keeps the pressure at $10 \mathrm{mmHg}$ and lasts for at least 10 years [3], a one off long lasting treatment that abolishes progression that is cheap safe and effective. But probably relatively few patients actually need their pressure lowered so much to achieve a reduction in the rate of progression compatible with a sighted lifetime.

The aim of this article is to document the evolution of high-quality evidence of the effectiveness of our interventions for open angle glaucoma from the first published systematic review on this question in 1993 to the present day. In doing so, we hope to summarise the important remaining uncertainties and set standards for the research we need to resolve them.

\section{Evidence that lowering the pressure reduces the risk of progression}

\section{The first systematic review-Rossetti (1993)}

Because intraocular pressure still seems to be the only modifiable risk factor for progression, perhaps it is not surprising that so many trials have chosen lowering of pressure as the primary outcome. But since Hollows and Graham [4], we have understood that pressure is not the disease and to understand whether treatment is actually effective, we need to 
measure function and progression. This point was made forcibly by Rossetti et al. in the first published systematic review in Ophthalmology in 1993 [5]. Out of more than a hundred RCTs, only five assessed the effect of lowering pressure on disease progression and those, small and underpowered, were inconclusive. So, at that point there was little or no certainty that lowering the pressure actually saved sight.

\section{Ocular Hypertension Treatment Study (OHTS) (2002)}

Great minds were thinking alike and as we can see from Quigley and Rossetti's exchange of letters in the New England Journal of Medicine [6], plans were already in place for the Ocular Hypertension Treatment Study [7].

At the time, this was thought to be the only possible ethical design of a randomised controlled trial on glaucoma progression. Such was the anxiety about leaving a potentially blinding disease untreated in a control arm, participants were selected for having had elevated pressure but no evidence of progression for at least 2 years before entering the study. Ironically, this meant participants were selected as being most resistant to the effects of pressure and unwittingly, a population was included in which the effects of treatment were going to be harder to identify. Hollows [4] had pointed out in 1966 that glaucoma appeared to be a disease in which for some, the optic nerve is more vulnerable to the effects of pressure than others and that what was needed was a kind of stress test which could identify such vulnerable nerves [2]. Those selected for OHTS were therefore least likely to show the benefit of pressure reduction and this may explain in part why the "number needed to treat" (NNT) from the study is so high. For prevention of progression based on the development of a visual field defect, 50 persons with pressures greater than 24 for 2 years before entering the study had to have it lowered by at least $20 \%$ to prevent one person developing a field defect. Despite this, a small absolute reduction in what was a low baseline risk of progression was identified. What was heard was the dramatic relative risk reduction of $50 \%$ and the very modest absolute risk reduction of $2-5 \%$ was less loudly announced.

\section{Collaborative Normal Tension Glaucoma Trial 1998}

But there had been another important trial before OHTS from the Collaborative Normal Tension Study Group [8]. Patients whose glaucoma progresses in the absence of elevated pressure presented a different ethical dilemma and perhaps it was more acceptable to randomise a single eye of such a patient to have the pressure reduced surgically or to be left to standard medical management for the control group. The problem was that the cataract often induced by the surgery obscured the possible benefit of the intervention on the progression of field loss and the possible benefit could only be detected in a post hoc analysis controlling for this effect. An alternative way of interpreting this was that cataract surgery was an important component of the effectiveness of the treatment of patients with "normal tension" disease.

\section{Advanced Glaucoma Intervention Study (AGIS) (1998)}

The dilemma of the optimal treatment sequence in people with established glaucoma for whom medical treatment alone had failed was addressed in the Advanced Glaucoma Intervention Study [9]. In retrospect it is easy to be critical of the complexity of the design of this study and there are important lessons to be learnt about the advantages of keeping trials simple. A major problem arose from the randomisation of eyes not people and the non-random allocation of the second eye to the opposite treatment of the first in those who had two eligible eyes. It was an important attempt to look at the difference in outcomes of treatment between black and white patients, yet race was not used to stratify the randomisation to ensure equal numbers of each race in either arm. The compared interventions were essentially two different sequences of surgical or laser treatment comparing trabeculectomy first to Laser trabeculoplasty. Surgical outcomes were poor in black patients and those receiving laser first had less deterioration but the most cited article emerging from this trial reported the nonrandomised observation of the relationship between risk of field progression and intraocular pressure. This offered quite strong but indirect evidence of the relationship between pressure reduction and progression [10].

\section{Early Manifest Glaucoma Trial (EMGT) (2002)}

The Early Manifest Glaucoma Trial [11], by selecting participants from a population based survey with an early diagnosis of OAG independent of pressure level meant population selected represents exactly those we wish to identify and successfully treat. But again, the opportunity to make it double masked and placebo controlled was lost in the nature of the design. Dummy laser treatment and placebo drops could have been offered to the control arm but the investigators believed that the visual field test resultsthe primary outcome measure-could/would not be influenced by participants being aware of their treatment status, and that masked readers of the field test result could not be 
influenced by knowledge of the study arm. The treatment, Laser trabeculoplasty and Betaxolol, might be argued by some to be not the most effective treatment options available at the time yet this did simply reflect current practice in Sweden. Optic nerves vulnerable to the effect of pressure were not excluded by the population sampling used to recruit participants and hence the observed effect sizes were much greater with NNT to reduce the risk of progression of five or less.

\section{European Glaucoma Prevention Study (EGPS) (2005)}

The European Glaucoma Prevention Study [12] fell into the same trap as the OHTS study probably selecting patients whose optic nerves were relatively resistant to the effects of pressure but at least it was double masked and placebo controlled. This was impossible for OHTS because of the design of achieving a $20 \%$ reduction in pressure by whatever means in the intervention arm. What was striking about the EGPS was the substantial placebo effect which together with a high attrition rate, meant that a significant clinical and statistical difference between the treatment arms was not observed.

\section{The next systematic reviews-Maier (2005) and Vass (2007)}

So, had Rosetti's question been answered? Maier's review [13] using Cochrane methods but published outside the library concluded; - Yes; in so far as we now had convincing evidence that lowering pressure reduced both the risk of developing glaucoma and its progression once incident but this only with certainty in persons with elevated pressure. A less certain effect compatible with none was observed in a subgroup with pressures which remained in the normal range.

Vass's Cochrane review [14] agreed but also, because it included head to head trials, raised the important question of the relative effectiveness of pressure lowering medications on the progression of the disease. Two interventions may equally lower pressure but would the effect be the same on field progression? The evidence for this was lacking, and is still lacking now.

And what about a placebo effect? No difference (beyond what could easily be explained by chance) in risk of developing glaucoma was observed in the double masked EGPS possibly because a significant reduction in pressure in the placebo group was observed. Others suggested the intervention-Dorzolamide $2 \%$-was not a very powerful pressure lowering agent.
By now, Latanoprost was licensed and in common use (and was used in the EMGT when pressures went too high). Licensing was on the basis of pressure reduction not disease progression however.

\section{United Kingdom Glaucoma Treatment Study (UKGTS) (2017)}

EMGT had successfully set the precedent that it was ethical to randomise participants with early glaucoma to treatment or none and a significant proportion of those left untreated showed no evidence of progression in 5 years. What was needed now was a properly designed and powered trial which compared current first line treatment, Latanoprost to placebo in a double masked fashion and hence the next important trial - the UK Glaucoma Treatment Study [15].

UKGTS used many of the best aspects of the design of the EMGT (meaning that its results could be meta-analysed) in terms of measuring progression and includable participants were representative of newly diagnosed presenting to several different NHS clinics with early open angle glaucoma. Pfizer made the trial happen by providing funding and logistic support (the placebo) but had no influence on the design, conduct or analysis of the study. Progression occurred in both groups but it was possible to see a difference in the rate after only a year of follow up. So now, a randomised controlled trial of minimal risk of bias had shown an indisputable reduction in the risk of progression by the lowering of intraocular pressure using current first line treatment. In the process, much had been learnt about the measurement of progression and how this might be made more efficient.

\section{Further reviews-Burr (2012), Rolim di Moura (2017) and the NICE Glaucoma Guidelines (2009)}

The glaucoma component of the sight loss and vision priority setting partnership in 2013 [16] clearly identified the question most sufferers of the disease most wanted answered. Not which drug lowered the pressure more than any other but which intervention was the best in preventing progression. Cochrane reviews comparing medicine, surgery and laser $[17,18]$ were inconclusive in terms of risk of progression, mainly because it had not been measured in most studies. Burr's review comparing medicine and surgery included a few important trials which did -notably the earlier Moorfields Laser/Medicine/Surgery trial [19] and the Collaborative Initial Glaucoma Treatment Study [20]. Though the earlier trial which compared surgery to less effective medicines and laser suggested surgery was more 
effective, the later CIGTS probably found evidence of no difference in progression risk. Burr's review identified some key gaps in the evidence, however. Since surgery in practice is usually reserved for more advanced disease, was there any evidence to compare surgery as a first line treatment versus standard medical management when the patient presents late? The absence of an answer to this important question lead later to the Treatment of Advanced Glaucoma Study (TAGS) trial [21], which will soon report its findings.

Rolim Di Moura's review on Laser trabeculoplasty could not find sound evidence of laser being more or less effective than standard medical treatment but highlighted the lack of good trials comparing modern laser treatment-(e.g. SLT) to modern medications-e.g. prostaglandins. This uncertainty was highlighted as a research priority in the first version of the NICE Guidelines for Chronic Open Angle Glaucoma [22]. Though limited evidence of the effectiveness of SLT existed in terms of its effect on pressure, there was little on the risk of progression and no good head to head comparisons with drops on outcomes of importance to patients and providers of care. A once off treatment, painless and safe is an attractive alternative to starting drops and may have a less detrimental effect on quality of life. This important question has been addressed by the LiGHT trial which recently published its findings, important and sound enough to change practice, in the Lancet [23].

\section{Systematic reviews of surgical trials in glaucoma}

There are many reviews looking at means for improving the outcome of glaucoma surgical interventions or comparing devices.

Trials and reviews on wound healing modification using antimetabolites or Beta radiation are now quite old. Both 5 Fluorouracil after and during surgery [24] and Mitomycin C [25] could be shown to be effective but both also with significant adverse effects and the certainty of the estimates was not high because of significant risk of bias in many studies. Interestingly, the superiority of MMC over 5FU [26] could not be clearly demonstrated in terms of the effect on reducing the risk of failure but if patient orientated outcomes had been compared, perhaps a clear preference for an interoperative application of a sponge to numerous painful postoperative injections would have shown a clear difference.

Few reviews contain enough trials of sufficient quality to be able to draw conclusions of any certainty and these include reviews on non-penetrating surgery [27], aqueous shunts [28] and whether Mitomycin improves shunt outcomes [29], and Device Modified Trabeculectomy [30]. Even a difference in Limbus and Fornix based conjunctival flaps for trabeculectomy could not be determined with any certainty [31]. This is mainly due to the poor quality of both the conduct and reporting of many of the trials.

\section{Minimally invasive glaucoma surgery}

Current attention on surgical intervention has shifted to Minimally Invasive Glaucoma Surgical devices because if there is a magic bullet to solve the global challenge of preventing blindness from glaucoma, the belief is that the "10:10:10:10" intevention is some such device.

There is a suite of ongoing Cochrane reviews on the various types of minimally invasive surgery including Trabectome, Hydrus, Endolaser cyclophotocoagulation, Xen and Infocus, Istent, Cypass and others as they emerge [32-37]. It is early days and many trials are ongoing but it is hoped these reviews can be kept up to date as the evidence emerges and modern practice properly informed. Cochrane is exploring the possibility of automated updating of reviews- "live" reviews-and these reviews and the MIGS consortium review authors might make a good team to take this on.

\section{Remaining important uncertainties}

A network meta-analysis of drugs for lowering pressure could conclude that prostaglandin analogues (PGAs) were the best class and of them, Bimatoprost may lower the pressure the most [38]. Strong caveats on the quality of the studies in the meta-analysis however means that this conclusion can not be relied on with any certainty and observed differences within classes may not be clinically meaningful. And anyway, it does not answer the question which drugs work best in terms of reducing the risk of progression. Leo Schmetterer pointed this out in an important editorial in 2012 [39] citing studies on systemic hypertension which showed similar effectiveness in blood pressure reduction but important differences in the most important outcome death from stroke or heart disease. Much more recent evidence that PGAs reduce corneal hysteresis is yet another reason to doubt observations about the most effective agent to lower pressure when some of that is explained by the mechanical effect of softening the cornea [40].

For years there has been a dream that drugs as well as lowering pressure might have a miraculous neuroprotective effect on the optic nerve but the Cochrane review on Neuroprotection [41] was inconclusive. This hypothesis was the basis of the Low-Pressure Glaucoma Treatment Study trial which compared the alpha agonist Brimonidine head to head with Timolol [42]. There was a hope or belief that the former has a neuroprotective action in addition to its 
pressure lowering properties. The trial showed a startling difference in risk of progression in favour of Brimonidine. But it was fatally flawed mainly because of severe and unequal attrition in the arms of the trial probably because Brimonidine is the most intolerable of all our topical agents for glaucoma. But if the observed difference turned out to be genuine, should we conclude it was a protective effect of Brimonidine or a harmful effect of Timolol? This is a very serious concern since the well known side effects of beta blockers - the slowing of the heart rate and potential dips in blood pressure-could possibly be harmful in terms of progression risk. This might be a more important and compelling hypothesis to test.

\section{Work on the European Glaucoma Society (EGS) Guidelines}

The current version of the EGS guidelines [43] is due for an update with an anticipated publication date in mid 2020. Current standards for developing trustworthy clinical practice guidelines strongly encourage guideline developers to use evidence from high-quality systematic reviews informing guideline recommendations [44]. Accordingly, the EGS has partnered with CEV@US (Cochrane Eyes and Vision's US satellite) to obtain systematic reviews relevant to forthcoming glaucoma guidelines. This partnership is modelled after the partnership that CEV@US has established with the American Academy of Ophthalmology (AAO). The 2016 cataract, 2017 refractive error, and 2018 cornea AAO Preferred Practice Pattern (PPP) guidelines demonstrate the success of this collaboration [45-47]. EGS guideline panel members are working with CEV@US to systematically identify relevant and reliable systematic reviews for glaucoma, using pre-specified criteria, and to generate a summary of each reliable systematic review that will be used by expert clinicians in the new version of the EGS guidelines.

\section{Outcomes in trials and systematic reviews}

There is a large heterogeneity in outcomes used for glaucoma trials [48]. This variability is common in all health areas and highlights the difficulties when comparing the effectiveness of different interventions, synthesising evidence, and informing clinical practice and policy.

There is a growing recognition that insufficient attention has been paid to the selection of outcomes and their domains when conducting a clinical trial [49]. The identification of important, core outcomes that are relevant to patients, clinicians and policy makers is being promoted by the Core Outcome Measures in Effectiveness Trials (COMET) initiative [50]. COMET was launched in January 2010 to address this lack of standardisation and to develop a minimum set of measures named "core outcome sets" to be reported as a minimum in all studies within an area of health. There is an expectation that the core outcomes will be used both in trials and systematic reviews to allow the results of studies to be compared and combined.

\section{Conclusion}

So, the need for high-quality comparative effectiveness trials of glaucoma treatments using COMET recommended outcomes-visual field progression and structural measurements of the nerve fibre layer using OCT-is now paramount. Encouraging progress is being made. The NIHR has made an enormous difference and has stepped up into the vacuum created by the NEI apparently being unwilling to fund many trials. However, in eye research we lack the equivalent of the huge charities funding research in Cancer, Heart Disease and even hearing loss. Fight for Sight could and should become as big as these but until they do, getting trials funded will continue to be a huge struggle with only government sources and industry with sufficient capacity. Glaucoma is a significant public health problem which lacks any coherent public health strategy and the impact of sight loss from the disease on quality of life is massive. Other aspects of glaucoma: angle closure, screening, primary care and congenital glaucoma all need massive investment so that the evidence base can improve. In order to make this happen, we need a louder voice.

Funding RW is funded by the Department of Health through the award made by the National Institute for Health Research to Moorfields Eye Hospital NHS Foundation Trust and UCL Institute of Ophthalmology for a Specialist Biomedical Research Centre for Ophthalmology. The views expressed in this publication are those of the authors and not necessarily those of the Department of Health.

\section{Compliance with ethical standards}

Conflict of interest The authors declare that they have no conflict of interest.

Publisher's note Springer Nature remains neutral with regard to jurisdictional claims in published maps and institutional affiliations.

\section{References}

1. Law A, Lindsley K, Rouse B, Wormald R, Dickersin K, Li T. Missed opportunity from randomised controlled trials of medical interventions for open-angle glaucoma. Br J Ophthalmol. 2017; 101:1315-7. 
2. Fraser S, Bunce C, Wormald R, Brunner E. Deprivation and late presentation of glaucoma: case-control study. $\mathrm{Br}$ Med $\mathrm{J}$. 2001;322:639.

3. Steedman MR, Taylor K, Kurek N, Khaw PT. Bright future: a new vision for eye health. Doha, Qatar: World Innovation Summit for Health; 2018. ISBN 978-1-912865-03-1

4. Hollows FC, Graham PA. Intra-ocular pressure, glaucoma, and glaucoma suspects in a defined population. Br $\mathrm{J}$ Ophthalmol. 1966;50:570-86.

5. Rossetti L, Marchetti I, Orzalesi N, Scorpiglione N, Torri V, Liberati A. Randomized clinical trials on medical treatment of glaucoma: are they appropriate to guide clinical practice? Arch Ophthalmol. 1993;111:96-103.

6. Rossett L, Orzales N, Liberat A. The medical treatment of openangle glaucoma. N Engl J Med. 1993;328:1097-106.

7. Kass MA, Heuer DK, Higginbotham EJ, Johnson CA, Keltner JL, Miller JP, et al. The ocular hypertension treatment study: a randomized trial determines that topical ocular hypotensive medication delays or prevents the onset of primary open-angle glaucoma. Arch Ophthalmol. 2002;120:701-13.

8. Collaborative Normal-Tension Glaucoma Study Group. The effectiveness of intraocular pressure reduction in the treatment of normal-tension glaucoma. Am J Ophthalmol. 1998;126:498-505. ISSN 0002-9394

9. The AGIS investigators. The advanced glaucoma intervention study (AGIS): 4. comparison of treatment outcomes within race: Seven-year results. Ophthalmology. 1998;105:1146-64. https:// doi.org/10.1016/S0161-6420(98)97013-0. ISSN 0161-642.

10. Nouri-Mahdavi Kouros, Hoffman Douglas, Coleman AnneL, Liu Gang, Li Gang, Gaasterland Douglas et al. Predictive factors for glaucomatous visual field progression in the Advanced Glaucoma Intervention Study. Ophthalmology. 2004;111: 1627-35. https://doi.org/10.1016/j.ophtha.2004.02.017. ISSN 0161-6420.

11. Heijl A, Leske MC, Bengtsson B, Hyman L, Hussein M.Early Manifest Glaucoma Trial Group Reduction of intraocular pressure and glaucoma progression: results from the Early Manifest Glaucoma Trial. Arch Ophthalmol. 2002;120:1268-79.

12. The European Glaucoma Prevention Study (EGPS) Group. Results of the European Glaucoma Prevention Study. Ophthalmology. 2005;112:366-75. https://doi.org/10.1016/j.ophtha.2004. 11.030 .

13. Maier Philip C, Jens Funk, Schwarzer Guido, Antes Gerd, FalckYtter YngveT. Treatment of ocular hypertension and open angle glaucoma: meta-analysis of randomised controlled trials. Br Med J. 2005;331:134.

14. Vass C, Hirn C, Sycha T, Findl O, Sacu S, Bauer P, et al. Medical interventions for primary open angle glaucoma and ocular hypertension. Cochrane Database of Systematic Reviews. 2007: CD003167. https://doi.org/10.1002/14651858. CD003167.pub3.

15. Garway-Heath DF, Crabb DP, Lascaratos G, Amalfitano F, Anand $\mathrm{N}$, Azuara-Blanco A, et al. Latanoprost for open-angle glaucoma (UKGTS): a randomised, multicentre, placebo-controlled trial. Lancet. 2015;385:1295-304. https://doi.org/10.1016/S0140-6736 (14)62111-5.

16. Rowe F, Wormald R, Cable R, Acton M, Bonstein K, Bowen M, et al. The sight loss and vision priority setting partnership (SLVPSP): overview and results of the research prioritisation survey process. BMJ Open. 2014;4:e004905.

17. Burr J, Azuara-Blanco A, Avenell A, Tuulonen A. Medical versus surgical interventions for open angle glaucoma. Cochrane Database Syst Rev. 2012:CD004399. https://doi.org/10.1002/ 14651858.CD004399.pub3.

18. Rolim de Moura CR, Paranhos Jr A, Wormald R. Laser trabeculoplasty for open angle glaucoma. Cochrane Database of
Systematic Reviews 2007:CD003919. https://doi.org/10.1002/ 14651858.CD003919.pub2.

19. Migdal C, Gregory W, Hitchings R. Long-term functional outcome after early surgery compared with laser and medicine in open-angle glaucoma. Ophthalmology. 1994;101:1651-6.

20. Lichter PR, Musch DC, Gillespie BW, Guire KE, Janz NK, Wren PA. et al. the CIGTS Study Group. Interim clinical outcomes in the collaborative initial glaucoma treatment study comparing initial treatment randomized to medications or surgery. Ophthalmology. 2001;108:1943-53. https://doi.org/10.1016/S0161-6420 (01)00873-9.ISSN 0161-6420.

21. King AJ, Fernie G, Azuara-Blanco A, Burr JM, Garway-Heath T, Sparrow JM, et al. Treatment of Advanced Glaucoma Study: a multicentre randomised controlled trial comparing primary medical treatment with primary trabeculectomy for people with newly diagnosed advanced glaucoma—study protocol. Br J Ophthalmol. 2018;102:922-8.

22. National Institute of Clinical Excellence. Glaucoma: diagnosis and management of chronic open angle glaucoma and ocular hypertension. http://www.nice.org.uk/nicemedia/pdf/CG85QuickRefGuide. pdf (2009)

23. Gazzard G, Konstantakopoulou E, Garway-Heath D, Garg A, Vickerstaff V, Hunter R, et al. LiGHT Trial Study Group. Selective laser trabeculoplasty versus eye drops for first-line treatment of ocular hypertension and glaucoma (LiGHT): a multicentre randomised controlled trial. Lancet 2019;393:1505-16.

24. Green E, Wilkins M, Bunce C, Wormald R. 5-Fluorouracil for glaucoma surgery. Cochrane Database Syst Rev. 2014: CD001132. https://doi.org/10.1002/14651858.CD001132.pub2.

25. Wilkins M, Indar A, Wormald R. Intraoperative Mitomycin C for glaucoma surgery. Cochrane Database Syst Rev. 2005: CD002897. https://doi.org/10.1002/14651858.CD002897.pub2.

26. Cabourne E, Clarke JCK, Schlottmann PG, Evans JR. Mitomycin $\mathrm{C}$ versus 5-Fluorouracil for wound healing in glaucoma surgery. Cochrane Database Syst Rev. 2015: CD006259. https://doi.org/ 10.1002/14651858.CD006259.pub2.

27. Eldaly MA, Bunce C, ElSheikha OZ, Wormald R. Non-penetrating filtration surgery versus trabeculectomy for open-angle glaucoma. Cochrane Database Syst Rev. 2014: CD007059. https://doi.org/10.1002/14651858.CD007059.pub2.

28. Tseng VL, Coleman AL, Chang MY, Caprioli J. Aqueous shunts for glaucoma. Cochrane Database Syst Rev. 2017: CD004918. https://doi.org/10.1002/14651858.CD004918.pub3.

29. Foo VHX, Htoon HM, Welsbie DS, Perera SA. Aqueous shunts with mitomycin $\mathrm{C}$ versus aqueous shunts alone for glaucoma. Cochrane Database Syst Rev. 2019:CD011875. https://doi.org/10. 1002/14651858.CD011875.pub2.

30. Wang X, Khan R, Coleman A. Device-modified trabeculectomy for glaucoma. Cochrane Database Syst Rev. 2015:CD010472. https://doi.org/10.1002/14651858.CD010472.pub2.

31. Al-Haddad C, Abdulaal M, Al-Moujahed A, Ervin AM. Fornixbased versus limbal-based conjunctival trabeculectomy flaps for glaucoma. Cochrane Database Syst Rev. 2015:CD009380. https:// doi.org/10.1002/14651858.CD009380.pub2.

32. Hu K, Gazzard G, Bunce C, Wormald R. Ab interno trabecular bypass surgery with Trabectome for open angle glaucoma. Cochrane Database Syst Rev. 2016:CD011693. https://doi.org/10. 1002/14651858.CD011693.pub2.

33. Otarola F, Hu K, Gazzard G, Bunce C. Ab interno trabecular bypass surgery with Schlemm's Canal Microstent (Hydrus) for open angle glaucoma. Cochrane Database Syst Rev. 2017: CD012740. https://doi.org/10.1002/14651858.CD012740.

34. Tóth M, Shah A, Hu K, Bunce C, Gazzard G. Endoscopic cyclophotocoagulation (ECP) for open angle glaucoma and primary angle closure. Cochrane Database Syst Rev. 2019: CD012741. https://doi.org/10.1002/14651858.CD012741.pub2. 
35. King AJ, Shah A, Nikita E, Hu K, Mulvaney CA, Stead R, et al. Subconjunctival draining minimally-invasive glaucoma devices for medically uncontrolled glaucoma. Cochrane Database Syst Rev. 2018: CD012742. https://doi.org/10.1002/14651858. CD012742.pub2.

36. Le JT, Bicket AK, Wang L, Li T. Ab interno trabecular bypass surgery with iStent for open-angle glaucoma. Cochrane Database Syst Rev. 2019:CD012743. https://doi.org/10.1002/14651858. CD012743.pub2.

37. Sandhu A, Jayaram H, Hu K, Bunce C, Gazzard G. Ab interno supraciliary microstent surgery for open angle glaucoma. Cochrane Database Syst Rev. 2017:CD012802. https://doi.org/10. 1002/14651858.CD012802.

38. Li T, Lindsley K, Rouse B, Hong H, Shi Q, Friedman DS. et al. Comparative effectiveness of first-line medications for primary open-angle glaucoma: a systematic review and network metaanalysis. Ophthalmology. 2016;123:129-40. https://doi.org/10. 1016/j.ophtha.2015.09.005.ISSN 0161-6420.

39. Schmetterer L. Are all glaucoma drugs equally effective? Acta Ophthalmol. 2010;88:503.

40. Agarwal DR, Ehrlich JR, Shimmyo M, Radcliffe NM. The relationship between corneal hysteresis and the magnitude of intraocular pressure reduction with topical prostaglandin therapy. Br J Ophthalmol. 2012;96:254-7.

41. Sena DF, Lindsley K. Neuroprotection for treatment of glaucoma in adults. Cochrane Database Syst Rev. 2017:CD006539.

42. Krupin T, Liebmann JM, Greenfield DS, Ritch R, Gardiner S, Low-Pressure Glaucoma Study Group. A randomized trial of brimonidine versus timolol in preserving visual function: results from the Low-Pressure Glaucoma Treatment Study. Am J Ophthalmol. 2011;151:671-81.

43. European Glaucoma Society Terminology and Guidelines for Glaucoma, 4th ed. Br J Ophthalmol. 2017;101:73-195

44. Institute of Medicine. Clinical practice guidelines we can trust. Washington, DC: The National Academies Press; 2011.

45. Golozar A, Chen Y, Lindsley K, Rouse B, Musch DC, Lum F, et al. Identification and description of reliable evidence for 2016 American Academy of Ophthalmology preferred practice pattern cataract in the adult eye. JAMA Ophthalmol. 2018;136: $514-23$

46. Mayo-Wilson E, Ng SM, Chuck RS, Li T. The quality of systematic reviews about interventions for refractive error can be improved: a review of systematic reviews. BMC Ophthalmol 2017; 17:164

47. Saldanha IJ, Lindsley K, Lum F, Dickersin K. Systematic reviews addressing corneal disease: The reliability of the evidence. (In preparation)

48. Ismail R, Azuara-Blanco A, Ramsay CR. Consensus on outcome measures for glaucoma effectiveness trials: results from a Delphi and nominal group technique approaches. J Glaucoma 2016;25 (Jun):539-46.

49. Ismail R, Azuara-Blanco A, Ramsay CR. Variation of clinical outcomes used in glaucoma randomised controlled trials: a systematic review. Br J Ophthalmol. 2014;98:464-8.

50. Core Outcome Measures in Effectiveness Trials. 2011-2019. http://www.comet-initiative.org/ 